\title{
A INFORMAÇÃO COMO ELEMENTO DE INTEGRAÇÃO ENTRE PROPÓSITO, PROCESSOS E PESSOAS EM INSTITUIÇÕES BRASILEIRAS E PORTUGUESAS ${ }^{1}$
}

\author{
Antônio Rodrigues Andrade 2 \\ Catarina Roseira ${ }^{3}$
}

http://dx.doi.org/10.1590/1413-2311.172.63787

\begin{abstract}
RESUMO
A vantagem competitiva de uma organização, empresa pública ou privada, ou até mesmo uma nação, está passando a depender, cada vez mais, de sua capacidade de tomada de decisões, gerar estratégias e transformá-las em ações diárias. Dessa forma, o desdobramento do propósito por meio dos processos de negócio até as pessoas permite assegurar o desenvolvimento de ações de forma convergente e mais orientada ao alcance dos objetivos estratégicos da organização. Esta pesquisa tem por objetivo avaliar o papel da informação como elemento integrador do propósito, do processo e das pessoas em organizações de captação, processamento e disseminação de informação em organizações brasileiras e portuguesas. É uma pesquisa interdisciplinar e se insere no contexto da Ciência da Administração e da Ciência da Informação no aspecto em que a informação e seus fluxos colaboram com os vários componentes do processo de alinhamento estratégico da organização. $\mathrm{O}$ estudo de natureza exploratória adotou uma metodologia multicaso. Foram estudados seis casos: especificamente, três organizações brasileiras e três portuguesas. Os dados foram recolhidos através de entrevistas semiestruturadas com profissionais da gestão das organizações pesquisadas. Os casos foram analisados individualmente e, posteriormente, procedeu-se à sua análise comparativa. Os resultados obtidos mostram que, apesar da centralidade da informação no seu propósito estratégico, as organizações pesquisadas não utilizam a informação em sua gestão interna e não revelam a mesma efetividade que possuem na prestação desses serviços informacionais.
\end{abstract}

Palavras-chave: Alinhamento Estratégico. Propósito. Processo. Pessoas.

INFORMATION AS THE LINK BETWEEN PURPOSE, PROCESSES AND PEOPLE: A STUDY IN BRAZILIAN AND PORTUGUESE INSTITUTIONS

\footnotetext{
ABSTRACT

The competitive advantage of an organization, either public or private, or even a nation, is

${ }^{1}$ Recebido em 06/04/2016; aprovado em 26/05/2017.

${ }^{2}$ Universidade Federal do Estado do Rio de Janeiro - antonio.andrade@ unirio.br.

${ }^{3}$ Universidade do Porto - croseira@ @ep.up.pt.

REAd | Porto Alegre - Vol. 23 - No Especial - Dezembro 2017 - p. 292-316
} 
increasingly depending on their ability to take decisions, elaborate strategies and transform them into everyday actions. Thus, the outspread of purpose to people through business processes ensures the convergent development of actions aimed at the achievement of the strategic targets of the organization. This research aims to evaluate the role of information as the element that links purpose, process and people in funding organizations, and in the processing and dissemination of information in Brazilian and Portuguese Organizations. It is an interdisciplinary research and is within the contexts of Administration and Information Sciences in the aspect that information and its flows work with the various components of the strategic alignment of the organization. This exploratory study adopted a multi-case methodology. Six cases, specifically three Brazilian and three Portuguese Organizations, were studied. Data were collected through semi-structured interviews with management professionals of the organizations surveyed. The cases were analyzed individually and, subsequently, we proceeded to make a comparative analysis. The results obtained show that the organizations surveyed do not use the information in their internal management despite the importance of information in their purpose, and thus do not show the same effectiveness that they have in the provision of information services.

Keywords: Strategic Alignment. Purpose. Process. People.

\section{LA INFORMACIÓN COMO FACTOR DE INTEGRACIÓN ENTRE PROPÓSITO, PROCESOS Y PERSONAS: UN ESTUDIO EN INSTITUCIONES BRASILEÑAS Y PORTUGUESAS}

\section{RESUMEN}

La ventaja competitiva de una organización o empresa pública o privada, o incluso de una nación, depende cada vez más de su capacidad de tomar decisiones, crear estrategias y transformarlas en acciones diarias. De esta forma, el despliegue del propósito, a través de los procesos de negocio, hacia las personas permite asegurar el desarrollo de acciones de forma convergente y más orientada a alcanzar los objetivos estratégicos de la organización. Esta investigación tiene como objetivo evaluar el papel de la información como factor de integración del propósito, el proceso y las personas en organizaciones de captación, procesamiento y diseminación de información en Organizaciones Brasileñas y Portuguesas. Se trata de una investigación interdisciplinar integrada en los contextos de la Ciencia de la Administración y de la Ciencia de la Información, en el sentido en que la información y sus flujos colaboran con los componentes del proceso de alineamiento estratégico de la organización. El estudio de naturaleza experimental adoptó una metodología multi-caso. Fueron estudiados seis casos, específicamente tres organizaciones brasileñas y tres portuguesas. Los datos fueron recolectados a través de entrevistas semi-estructuradas con profesionales de la gestión de las organizaciones investigadas. Los casos fueron analizados individualmente $\mathrm{y}$, posteriormente, se procedió a un análisis comparativo. Los resultados obtenidos sugieren que, a pesar de la centralidad de la información en su propósito estratégico, las organizaciones investigadas no la utilizan en su gestión interna y no revelan la misma efectividad que poseen en la prestación de estos servicios de información.

Palabras-clave: Alineamiento Estratégico. Propósito. Proceso. Personas.

REAd | Porto Alegre - Vol. 23 - No Especial - Dezembro 2017 - p. 292-316 


\section{INTRODUÇÃO}

O termo informação ganhou grande relevância, principalmente, nos negócios nas décadas finais do século passado, quando a explosão informacional, potencializada pelas tecnologias emergentes, fez com que o seu tratamento ganhasse nova dimensão devido ao ritmo, cada vez mais crescente, da evolução tecnológica. A necessidade de investigação das propriedades da informação e seu comportamento, as forças que regem seu fluxo e os métodos para processá-la a fim de obter acessibilidade e utilização ótimas ganharam importância, muitas vezes, vital para a tomada de decisão e desenvolvimento de ações tanto operacionais quanto estratégicas. Isso se aplica a todos os setores.

A base para criar significado, construir conhecimento e tomar decisões que permitam o desenvolvimento das organizações está na forma sistemática do tratamento da informação. A vantagem competitiva das organizações está passando a depender, cada vez mais, de sua capacidade de tomada de decisões, de gerar estratégias e de transformar essas estratégias em ações diárias em que seus profissionais possam contribuir, gerando resultados significativos ao encontro de seus objetivos. Vemos a informação como objeto principal para que isso possa se concretizar.

A informação é um instrumento de integração fundamental que necessita ser avaliada no seu impacto produzido no processo de integração organizacional e, sob esse ponto de vista, as pessoas representam um papel importante no contexto. Assim, entende-se que a informação e, principalmente, a sua organização e o seu compartilhamento permitirão aos envolvidos a prática do planejamento, monitoramento e controle de forma consistente nas várias organizações públicas ou privadas, direta ou indiretamente.

O alinhamento estratégico visando à integração organizacional por meio da informação é o tema central da pesquisa. A informação desempenha papel essencial na integração das etapas. Assim, (a) a informação, na definição estratégica, cria as condições para uma resposta competitiva mais eficaz da organização em relação às exigências do ambiente; (b) a informação para a execução estratégica está relacionada à disseminação das definições estratégicas por toda a organização e à contribuição da criação de condições para a sua implementação; e (c) o feedback da informação (indicadores de desempenho) sobre o desempenho permite que se reconheçam as necessidades de modificações e ajustes nas definições quando se tornarem ineficazes (McGEE; PRUSAK, 1994).

O alinhamento estratégico é a essência da gestão estratégica. É por meio dele que se

REAd | Porto Alegre - Vol. 23 - No Especial - Dezembro 2017 - p. 292-316 
constrói a consistência entre planos, processos e decisões que apoiam as estratégias da organização. A fim de torná-lo eficaz, faz-se necessário o entendimento das estratégias e metas, e a utilização de indicadores de desempenho que possibilitem o monitoramento, a análise e a melhoria nos setores de trabalho, nos principais processos e na organização como um todo. E, nesse ponto, a informação desempenha um papel significativo (McGEE; PRUSAK, 1994).

É nesse contexto que esta pesquisa se insere, procurando descrever a situação de organizações de uso intensivo de informação quanto à sua atividade-fim. Apoia-se, sob a perspectiva da Administração, na gestão estratégica; e na gestão da informação, sob a perspectiva da Ciência da Informação.

Bibliotecas, museus e arquivos são organizações de captação, processamento e disseminação de informação. Possuem como objetivo primeiro, no caso das bibliotecas, a preservação, a atualização e a divulgação da coleção sob sua custódia. Os museus possuem o objetivo do estudo, da preservação e da divulgação da história e memória; e os arquivos, por sua vez, responsabilizam-se pela gestão, pelo recolhimento, pelo tratamento técnico e pela preservação documental.

Com o objetivo de descrever o papel da informação como elemento integrador do propósito, do processo e das pessoas em organizações de captação, processamento e disseminação de informação com uma visão multidisciplinar, esta pesquisa avalia a utilização da informação no alinhamento estratégico de instituições brasileiras e portuguesas. Busca resposta para a questão: instituições com uso intensivo de informação na sua atividade-fim também demonstram a mesma efetividade no uso da informação em sua gestão?

Em Oliveira, Pinheiro e Andrade (2011), foram estudados os conceitos da Ciência da Informação em revistas de Administração, bem como os conceitos de Administração na Ciência da Informação. A pesquisa preocupou-se, ainda, em identificar conceitos de autores de outras áreas nessas revistas. Foram identificados 15 autores de Ciência da Informação nas revistas de Ciência da Administração, com 58 citações. Quanto à Ciência da Administração, foram identificados 39 autores, com 220 citações, nas revistas de Ciência da Informação. Em relação às outras áreas, 8 autores apresentaram conceitos relacionados à Ciência da Administração e à Ciência da Informação, com 73 citações.

Durante o período da pesquisa, procedeu-se a um levantamento bibliográfico complementar nas bases de dados disponíveis no Portal da CAPES, em Administração e Ciência da Informação, a respeito do "alinhamento estratégico em museus, arquivos e

REAd | Porto Alegre - Vol. 23 - No Especial - Dezembro 2017 - p. 292-316 
bibliotecas". Não foram identificadas fontes significativas que contribuíssem para a identificação do papel da informação no alinhamento estratégico nas instituições estudadas.

$\mathrm{O}$ artigo está estruturado em quatro seções além desta introdução. A primeira seção apresenta a revisão bibliográfica e demonstra a construção das bases da pesquisa complementada. A segunda seção apresenta a abordagem metodológica. A terceira seção apresenta os resultados do estudo e a sua discussão quanto à integração entre propósito, processos e pessoas nas instituições estudadas. E a quarta seção expõe as considerações finais.

\section{ALINHAMENTO ESTRATÉGICO E INFORMAÇÃO}

A empresa possui uma interação dinâmica com seu meio ambiente, sejam clientes, fornecedores, concorrentes, entidades sindicais, órgãos governamentais e outros agentes externos. Além disso, possui uma estrutura de funcionamento composta por diversas unidades relacionadas entre si, que atuam de forma harmônica e estão orientadas para objetivos definidos, não só para a organização como para seus participantes (PORTER, 1998). É nesse ambiente que o alinhamento estratégico deve se instalar com um modelo de gestão que o torne realidade.

Mesmo com a ausência de consenso quanto a uma teoria de alinhamento, é importante considerá-lo de forma a que os recursos da organização voltem a uma única direção, procurando garantir a melhoria da performance organizacional (PRIETO; CARVALHO, 2004; BUNGAY, 2011).

O alinhamento estratégico, ainda, é um tema carente na literatura (GONÇALVES, 2000). Também, Mintizberg e Quinn (2001) discutem a lacuna existente entre as fases de elaboração e de implementação da estratégia corporativa, e afirmam que esse é um dos principais assuntos a serem tratados nos próximos anos.

O processo de alinhamento estratégico evidencia aspectos como a necessidade de definir os fatores críticos de sucesso do negócio, a efetividade do processo de comunicação e do seu fluxo, controle da estratégia e utilização de métricas, bem como as competências individuais e os sistemas de recompensa (GALBRAITH, 1977; GALBRAITH, DOWNEY, KATES, 2011; KAPLAN e NORTON, 1997), o que leva a uma perspectiva tanto externa quanto interna do alinhamento da organização.

Assim sendo, o desdobramento do propósito, por meio dos processos do negócio até as pessoas, permite garantir a visão do todo, substituindo a míope visão vertical por uma

REAd | Porto Alegre - Vol. 23 - No Especial - Dezembro 2017 - p. 292-316 
ampla visão horizontal das instituições, o que assegura o desenvolvimento de ações de forma convergente e mais orientadas ao alcance dos objetivos estratégicos da organização. A necessidade de as organizações promoverem o alinhamento de suas estratégias com os processos internos e com as pessoas tem se configurado como uma necessidade crescente (MORRISON et al., 2011).

Sempre presente em todos os períodos históricos, a informação se tornou, ao final do século passado, um relevante fator de produção. Em um mercado cada vez mais globalizado e competitivo, a utilização da informação assume importante papel na orientação das estratégias das organizações. Vive-se uma fase cujas transformações se aceleram nas tecnologias de informação, na comunicação e na configuração da economia.

A informação tem se mostrado importante para a Administração e, em especial, para a gestão estratégica. A Administração é a interpretação dos objetivos propostos pela empresa por meio do planejamento, da organização, da direção e do controle de todos os esforços realizados em todas as áreas e em todos os níveis da organização, a fim de alcançar tais objetivos de maneira mais adequada à situação (CHIAVENATO, 2003). Por seu turno, a gestão estratégica pode ser entendida como a criação, a escolha e a formulação da estratégia, a tradução em ação por meio da consecução das necessárias mudanças e, por fim, a monitoração e a avaliação da sua efetividade. A gestão estratégica e a gestão da informação devem caminhar lado a lado para que o alinhamento se realize (McGEE; PRUSAK, 1994; FERLIE; ONGARO, 2015).

Para a consecução da gestão estratégica, Heijden (2009) apresenta uma classificação genérica que esclarece as formas dos gestores pensarem a realização de suas intenções e ações estratégicas denominadas de racional, evolucionária e processual. A abordagem racional trata o pensamento e a ação separadamente. Parte do princípio de que existe uma resposta, e a tarefa do estrategista é encontrá-la. A premissa básica é que existe sempre uma solução melhor e que a tarefa do estrategista, que representa e pensa em nome da organização inteira, é chegar ao mais próximo dela, considerando a melhor utilização dos recursos disponíveis. Essa abordagem compara a organização a uma máquina. A ênfase na utilização de modelos matemáticos e de simulação é uma prática normal (HEIJDEN, 2009).

Como a abordagem racional não consegue responder determinadas questões envolvidas no desenvolvimento da estratégica das organizações, surge a abordagem evolucionária. Ela dá maior ênfase à natureza complexa do comportamento emergente nas organizações, preconizando a necessidade de um processo de experimentação ao acaso e

REAd | Porto Alegre - Vol. 23 - No Especial - Dezembro 2017 - p. 292-316 
filtragem daquilo que é malsucedido. Nessa abordagem, predomina a visão de que não existe muito sentido em se dedicar esforço na tentativa de definição de estratégia, pois considera o mundo complexo para tentar controlá-lo, acreditando que o melhor é reagir na medida em que as coisas acontecem e esperar quais as mudanças que terão êxito. Com isso, dessa abordagem, emerge a possibilidade de constituição de um quadro de estratégias que são desenvolvidas para satisfazer às necessidades psicológicas dos gestores, de forma que possam se sentir no controle (HEIJDEN, 2009).

Por fim, a abordagem processual entende a organização como um sistema adaptável complexo, estando aberta ao ambiente, ajustando-se de acordo com o que nele percebe. Racionais e evolucionistas não se preocupam em como funciona o processo organizacional, já os processualistas incluem os processos internos da organização no contexto do planejamento (HEIJDEN, 2009).

Cada empresa incorpora um modelo de gestão que, ao longo do tempo, vai sendo alterado e ajustado de forma a melhor contribuir com os seus objetivos. O modelo de gestão não é único nem rígido e varia de organização empresarial para organização empresarial em função do desenvolvimento de variáveis internas e externas a ela (RODRIGUEZ, 2001), contudo a informação se faz presente independente do modelo de gestão que a organização adote.

As organizações possuem modelos de gestão que podem variar entre dois limites: o primeiro denominado toyotismo, que apresenta um novo paradigma produtivo decorrente das transformações sociotécnicas das empresas, pela intercessão do novo padrão tecnológico baseado na microeletrônica e nas tecnologias da informação; e outro que é denominado mecanicismo, em que as empresas se comparam ao fordismo, sendo o oposto das orgânicas ou denominadas por toyotismo. Esses extremos formam um contínuo em que as empresas se posicionam e organizam seus processos produtivos (TENÓRIO, 2000; FERREIRA et al., 2005; SOBRAL; PECI, 2013).

A informação representa importante papel em relação ao modelo de gestão utilizado nas organizações e deve ser gerenciada. O conceito de gestão da informação tem suas peculiaridades, sendo seu entendimento em Administração de forma diferente ao da Ciência da Informação. Na Administração, abrange o processo de coleta, armazenamento, tratamento e disseminação da informação no ambiente organizacional. Para a Ciência da Informação, a gestão da informação inclui todas as questões inerentes ao uso da informação, aspecto

REAd | Porto Alegre - Vol. 23 - No Especial - Dezembro 2017 - p. 292-316 
semelhante à Administração, e converge para os campos da gestão do conhecimento e da inteligência competitiva (OLIVEIRA; PINHEIRO; ANDRADE, 2011).

Sendo o alinhamento estratégico a essência da gestão estratégica que se une à gestão da informação para a promoção da integração organizacional, podem-se definir as seguintes etapas para a sua realização, segundo McGee e Pruzak (1994): (a) a informação na definição estratégica cria as condições para uma resposta competitiva mais eficaz da organização às exigências do ambiente; (b) a informação para a execução estratégica está relacionada à disseminação das definições estratégicas por toda a organização e à contribuição para a criação das condições para a sua implementação; e (c) o feedback da informação (indicadores de desempenho) sobre o desempenho permite que se reconheçam as necessidades de modificações e ajustes nas definições quando se tornarem ineficazes.

O alinhamento externo considera a empresa quanto ao seu ambiente de atuação, abordando a questão da vantagem competitiva com ênfase ao poder do mercado. Enquanto que o alinhamento interno considera a manutenção dos elementos internos durante a implementação da estratégia (PRIETO; CARVALHO, 2004).

O alinhamento estratégico ocorre na integração entre propósito, processos e pessoas e tem, na gestão por processos, o elo que permite a ligação entre a estratégia organizacional e seus colaboradores (MORRISOM et al., 2001). Portanto, conforme proposto nesta pesquisa, considera-se o alinhamento interno sem se desconsiderar a importância do alinhamento externo.

Sendo transdisciplinar, o processo é a sincronia entre insumos, atividades, infraestrutura e referências necessárias para adicionar valores ao ser humano e pode ser entendido como o conjunto de ações dispostas de forma a proporcionar um fluxo contínuo de informações, material e trabalho (pessoas e máquinas) que consomem recursos (tempo e dinheiro) a fim de gerar satisfação ao seu receptor (cliente, espaço de convivência e sociedade) (GONÇALVES, 2000; HARMON, 2007; KOHLBACHER, 2010; ROSEMANN; BROCKE, 2015).

As pessoas possuem uma característica importante no processo de alinhamento. São elas que fazem, efetivamente, a execução da estratégia acontecer e, assim, o desenvolvimento de competências e capacitação de pessoas ganha importância.

Segundo Zarafian (2001), a competência é um entendimento prático de situações que se apoia em conhecimentos adquiridos e os transforma na medida em que aumenta a diversidade das situações.

REAd | Porto Alegre - Vol. 23 - No Especial - Dezembro 2017 - p. 292-316 
O conceito de competência pode ser entendido com base em três dimensões: conhecimentos, habilidades e atitudes. Tal conceito abrange não só os conhecimentos técnicos, mas a cognição e as atitudes relacionadas ao trabalho. O conhecimento é o conjunto de informações assimiladas e estruturadas pelo indivíduo, através das quais ele processa a realidade, incluindo a capacidade de receber informações e integrá-las, o saber "o que" e o "por que". Habilidade é a capacidade de aplicar e utilizar o conhecimento produtivamente, contemplando técnica e aptidão. Já a atitude está relacionada às características afetivas e sociais do trabalho, ou seja, a identidade do indivíduo com os valores da organização, seu comprometimento e motivação para o atingimento dos resultados esperados (DURAND, 2006).

A implementação de boas práticas para o desenvolvimento de processos e a implementação de tecnologia que permita modificar o modo como as organizações gerem os seus colaboradores é um fator crítico para o sucesso nos negócios. A necessidade de as organizações promoverem o alinhamento de seus empregados às suas estratégias e aos seus objetivos tem se configurado como uma necessidade crescente. Para que se torne fonte de vantagem competitiva, a estratégia deve permear toda a organização. Portanto, ganha expressão, nesse momento, o desenvolvimento de competências e capacitação de pessoas (CARVALHO, PRIETO, BOUER, 2013).

Cabe destacar, ainda, o gerenciamento estratégico que tem evoluído, principalmente, no que se refere a indicadores de desempenho a partir da década de 1990 (CRISPIN e LUGOBONI, 2012).

Dois modelos se destacaram no final do século passado e, ainda, são utilizados pelas organizações nos dias de hoje: o Balanced Score Card (BSC) e o Hoshin Kanri ou Gerenciamento pelas Diretrizes. O primeiro foi desenvolvido por Kaplan e Norton nos Estados Unidos na década de 1990; e o segundo, baseado na metodologia do professor Yoji Akao no Japão na década de 1980 (AKAO, 1988; KAPLAN; NORTON, 1997).

O Balanced Score Card (BSC) procura ser mais do que um sistema de medidas tanto táticas quanto operacionais e tem sido adotado por organizações como um sistema de gestão estratégica. O Hoshin Kanri ou Gerenciamento pelas Diretrizes, em sua abordagem, da mesma forma apresenta uma metodologia de gestão que objetiva assegurar que a estratégia organizacional seja implementada com ampla participação da organização e seus colaboradores (KAPLAN; NORTON, 1997; CAMPOS, 1996).

REAd | Porto Alegre - Vol. 23 - No Especial - Dezembro 2017 - p. 292-316 
O $B S C$ é uma abordagem simples e rápida de ser aplicada, contudo pode haver dificuldades em traduzir os objetivos do negócio em objetivos operacionais. Por sua vez, o Hoshin Kanri possui uns processos, na sua abordagem, que definem os objetivos de mais alto nível de forma que se desdobrem até os operacionais, além de permitir que alterações sejam providenciadas quando os objetivos não são atingidos. Uma crítica feita ao Hoshin Kanri é a de que adota uma perspectiva funcional, enquanto o Balanced Score Card possui uma abordagem mais contemporânea. Apesar disso, a combinação das duas metodologias pode ser favorável à organização de forma a se complementarem, permitindo que o desdobramento estratégico e o processo decisório sejam mais efetivos (FITERMAN; SILVA, 2007).

Para Afonso (2014), a avaliação de desempenho tem papel importante para o atingimento do alinhamento estratégico. Em sua pesquisa, procura analisar a utilização de ferramenta de avaliação de desempenho. Identifica que, se a avaliação de desempenho e seus critérios não estiverem integrados ao alinhamento estratégico, prejudicará a sua realização.

Resumindo, são três as considerações que vêm ao encontro do que apresentam McGee e Prusak (1994):

a) a informação desempenha papel essencial na integração das etapas, criando sintonia para a definição estratégica, bem como possibilita as condições para uma resposta competitiva mais eficaz da organização às exigências do ambiente;

b) a informação na execução estratégica está relacionada à disseminação das definições estratégicas por toda a organização, contribuindo, assim, para a criação das condições da sua implementação; e, por fim,

c) a retroalimentação da informação com indicadores de desempenho permite o reconhecimento das necessidades de ajustes nas definições quando se tornarem ineficazes ou quando novas oportunidades surgirem.

Acrescente-se, ainda, Heijden (2009), quando afirma que o pensamento e a ação estratégica devem estar interligados em uma abordagem coerente para que o intento estratégico aconteça: o que confirma a primeira consideração mencionada. A segunda consideração pode ser entendida como a abordagem por processos em ação e promove a ligação entre a estratégia organizacional e seus colaboradores (MORRISOM et al., 2001). E a terceira consideração demonstra a importância das pessoas para o alinhamento estratégico e a necessidade de qualificação profissional orientada para a execução estratégica (ZARAFIAN, 2001; DURAND, 2006).

REAd | Porto Alegre - Vol. 23 - No Especial - Dezembro 2017 - p. 292-316 


\section{ABORDAGEM METODOLÓGICA}

As bibliotecas, os museus e os arquivos têm, no seu objetivo, a informação como principal elemento e são, em última análise, organizações de processamento e uso intensivo da informação. Esta pesquisa busca entender e descrever como as organizações atuam internamente, considerando a informação como elemento fundamental à realização do alinhamento estratégico. Busca resposta para a questão: instituições com uso intensivo de informação na sua atividade-fim, também, demonstram ter a mesma efetividade no uso da informação em sua gestão?

Sendo esse o problema ou questão basilar da pesquisa, foi estabelecido o objetivo de descrever o papel da informação na integração de propósito, processos e pessoas para o alinhamento estratégico em organizações de uso intensivo de informação. Para suporte ao estudo, foi proposto:

a) identificar as formas como as instituições estabelecem as estratégias;

b) identificar o processo de desdobramento estratégico no processo de gestão com foco na informação e

c) descrever o papel da informação para o alinhamento estratégico nas instituições pesquisadas.

A metodologia utilizada é um estudo de casos múltiplos enquadrados nas características da abordagem qualitativa. Os procedimentos técnicos envolveram estudos descritivos, pesquisa documental e entrevistas estruturadas com os gestores das instituições escolhidas. Foram realizadas entrevistas semiestruturadas com a direção, bem como com colaboradores em nível gerencial de cada instituição (ALVES-MAZZOT; GEWANDSNAJDER, 2000; YIN, 2001; CERVO; BERVIAN, 2002).

Foram estudadas organizações no Brasil e em Portugal. As instituições pesquisadas no Brasil foram o Museu Histórico Nacional e a Biblioteca Nacional, ambas vinculadas ao Ministério da Cultura, e o Arquivo Nacional, vinculado ao Ministério da Justiça. Em Portugal, as instituições pesquisadas foram o Museu Nacional Soares dos Reis, integrante da Direção Geral de Patrimônio Cultural do governo português, a Biblioteca Municipal do Porto e o Arquivo Geral, serviços da Câmara Municipal do Porto.

A pesquisa de campo se baseou nos procedimentos propostos por Alberti (1990). O primeiro procedimento foi a identificação dos profissionais das empresas pesquisadas. Em seguida, foi feita uma sondagem para a realização da pesquisa e a formalização dos convites

REAd | Porto Alegre - Vol. 23 - No Especial - Dezembro 2017 - p. 292-316 
de participação. Foram consultados dois profissionais de cada instituição pesquisada, na forma de entrevista.

O principal critério de seleção dos participantes foi uma consulta à instituição quanto à indicação dos gestores, considerando-se o tempo de experiência na organização e sua posição hierárquica, havendo preferência pelo ocupante de cargo ou função de gestão. Após o aceite dos participantes, foi formalizado o convite para a realização das entrevistas e foi encaminhado um resumo do assunto a ser desenvolvido no encontro.

O roteiro de entrevista foi dividido em três partes, levando-se em conta questões relacionadas com o propósito, os processos e as pessoas nas instituições. Foram elaboradas dez questões para propósito, relacionadas com planejamento estratégico, interação com os clientes/usuários e nível de inovação; quinze questões de processos, abordando temas como modelo de gestão, uso de tecnologia da informação, conectividade, acesso e disponibilidade da informação e controle. E mais dez questões do tópico Pessoas, buscando identificar a captação, avaliação e capacitação de talentos.

As entrevistas foram gravadas, transcritas e conferidas a fim de ser mantida a integridade da transcrição. No primeiro momento, a transcrição foi concentrada nas respostas do entrevistado às perguntas elaboradas. No segundo momento, realizou-se um ajuste nas respostas, considerando-se que, em certos momentos, algumas delas se sobrepuseram a outras perguntas, ou foram respostas complementares a anteriores.

Após essa etapa, foi desenvolvida a revisão do texto a fim de eliminar repetições ou outras inadequações que prejudicassem o entendimento do texto extraído da entrevista.

Concluídos esses procedimentos, o estudo apresenta interpretações objetivando avaliar e comentar, conforme o referencial apresentado na primeira parte, um conjunto de informações para revisão, reflexão e interpretação do objeto do estudo, ou seja, a informação na integração de propósito, processos e pessoas. A análise dos dados foi interpretativa, tomando-se, por base, as informações relatadas pelos entrevistados considerando o corpo de conhecimentos pertinentes ao assunto nos campos das ciências de administração e da informação.

\section{RESULTADO E DISCUSSÃO}

Foram considerados três aspectos para a construção da integração organizacional por meio da informação: propósito, processos e pessoas.

REAd | Porto Alegre - Vol. 23 - No Especial - Dezembro 2017 - p. 292-316 


\subsection{O PROPÓSITO}

O primeiro componente para a definição da existência do alinhamento estratégico é o propósito. Nele, ão encontrados os elementos que permitem avaliar a existência de uma formulação estratégica, bem como os mecanismos que permitiem à organização proceder à integração por meio do desdobramento estratégico.

A classificação que esclarece as formas com que os gestores pensam sobre a realização de suas intenções e ações estratégicas as denomina de racional, evolucionária e processual.

A abordagem racional trata o pensamento e a ação separadamente. Essa abordagem é a que mais se aproxima de duas instituições pesquisadas: o Arquivo Nacional e a Biblioteca Nacional. Apresentam elementos que permitem definir como racional o modelo de formulação e implementação estratégica das instituições.

O Museu Histórico Nacional, no Brasil, apresenta elementos mais próximos da abordagem processual: mais aberta ao ambiente e procurando se ajustar conforme o que nele é percebido.

A abordagem processual, diferentemente das outras e, em especial, do racional, entende que é possível se definirem estratégias ótimas como o proposto pelo paradigma racional. Entretanto, para que isso se torne possível, as organizações devem se tornar mais flexíveis, adaptáveis e capazes de aprender com seus próprios erros. O que é demonstrado pelo Museu Histórico Nacional, principalmente, quando se refere ao aprendizado que busca nas ações relacionadas aos seus clientes.

A abordagem racional, que trata o pensamento e a ação separadamente, é encontrada nas instituições portuguesas: no Arquivo, na Biblioteca e no Museu. Apresentam elementos que permitem definir como racional o modelo de formulação e implementação estratégicas das instituições portuguesas.

Duas instituições - Museu Histórico Nacional e Arquivo Nacional, ambas no Brasil, promovem a integração estratégica levando em consideração dois aspectos. O primeiro se refere à informação definida no plano estratégico, desdobrada em objetivos e metas correspondentes e alinhadas ao plano inicial. O segundo aspecto se refere às pessoas que participam do processo de planejamento que, conforme a instituição, podem-no fazer de forma mais ou menos ativa.

Cabe destacar que houve divergência de informações nas entrevistas realizadas na

REAd | Porto Alegre - Vol. 23 - No Especial - Dezembro 2017 - p. 292-316 
Biblioteca Nacional no Brasil. Enquanto uma entrevistada informou a existência do planejamento estratégico da instituição, a outra participante afirmou não reconhecer essa existência. Essa situação fragiliza a afirmação de que há desdobramento estratégico, pois ele se consolida com o conhecimento de todos a seu respeito na organização.

No Museu Histórico Nacional no Brasil, pode-se observar que se busca a integração organizacional. O que é fundamental para o alinhamento estratégico. Ela ocorre através de reuniões em todos os níveis, procurando garantir que todos tomem ciência e participem do movimento estratégico. As informações e as pessoas, em toda a instituição, mobilizam-se para o cumprimento das operações e projetos vinculados ao plano estratégico de forma orquestrada.

No Arquivo Nacional no Brasil, também existe a preocupação de utilização da informação e da participação das pessoas. A busca da integração organizacional é uma preocupação da direção, que reúne a administração intermediária no processo de formulação estratégica, mas a implementação é de responsabilidade dos gestores intermediários sem um procedimento sistêmico e sistemático, o que não garante, assim, a sua aplicação. A participação dos demais colaboradores da instituição depende do comportamento das chefias em informá-los e suas informações serem apresentadas em fóruns superiores.

Nas instituições portuguesas, merece destaque a atuação da Câmara Municipal. Possui um planejamento estratégico que permite às instituições a ela subordinadas terem um planejamento organizacional elaborado por meio do desdobramento do planejamento com seu ponto de partida na Câmara Municipal.

No planejamento estratégico da Câmara Municipal, são apresentados os objetivos estratégicos e o Balanced Scorecard (BSC). Contudo, o desdobramento dos objetivos estratégicos ocorre em cascata, do nível superior para os operacionais, à semelhança do Hoshin Kanry ou Gerenciamento pelas Diretrizes. Nota-se uma fusão entre as metodologias devido à configuração organizacional hierarquizada das instituições ligadas à Câmara Municipal do Porto, como é o caso do Arquivo Geral e da Biblioteca Municipal.

O Museu Nacional Soares dos Reis, instituição portuguesa, procura desenvolver o alinhamento sem uma metodologia definida, a partir do planejamento estratégico apresentado pela Direção Geral do Patrimônio Cultural. Contudo, o estudo de Santos e Varejão (2015) apresenta a existência de uma rigidez crescente expressa como uma incapacidade de definição de delegações que se acentuam em função da inexistência de elaboração e implementação, segundo os autores, de respostas estratégicas, rápidas e eficientes às crescentes exigências

REAd | Porto Alegre - Vol. 23 - No Especial - Dezembro 2017 - p. 292-316 
provocadas pelas transformações do campo dos museus.

À exceção do Arquivo do Porto, a realização de reuniões para a avaliação estratégica não é uma prática sistematizada. As reuniões ocorrem com mais frequência no nível operacional para resolução de questões relacionadas à busca da melhoria contínua da qualidade.

A comunicação por meio de Tecnologia da Informação não é explorada para a construção do alinhamento pelas três instituições brasileiras, que mais a utilizam para a operacionalização das ações e operações. O que também ocorre nas instituições portuguesas.

A busca de informações externas, principalmente, a do cliente, não é feita de forma proativa e, tampouco, a captura das informações recebidas é realizada de forma sistematizada pelas instituições, tanto brasileiras quanto portuguesas. As informações são recebidas por canais instituídos como Fale Conosco, e-mails e caixa de sugestões no dia a dia. As três instituições conhecem bem seus clientes, mas não os exploram no sentido de contribuírem com suas informações no processo estratégico. Não pode ser ignorado que ao ouvi-los, mesmo de forma reativa e com os meios que possuem, aproveitam-se as informações fornecidas para melhorias operacionais. Também, foi observado que os mesmos mecanismos são utilizados nas instituições portuguesas.

Quanto ao ouvir o cliente, nas instituições portuguesas, destacam-se dois aspectos. O primeiro é relacionado aos Arquivos e às Bibliotecas, que desenvolvem as pesquisas de satisfação de dois em dois anos; e a Câmara Municipal, que não tem um caráter de especificidade para a atuação das instituições, sendo desenvolvido de forma a não permitir uma atuação mais concreta tanto dos arquivos quanto das bibliotecas. No caso dos museus, está disponível uma pesquisa em todos os museus nacionais com o objetivo de verificar os usuários e seus hábitos e dar maior orientação a eles e aos serviços prestados por essas instituições em Portugal.

As instituições brasileiras estudadas dizem-se inovadoras, mas isso ocorre com limitações: inovar não é uma prática constante e comum, embora demonstrem ações nesse sentido, principalmente, a Biblioteca Nacional e o Museu Histórico Nacional.

Nota-se a mesma situação nas organizações portuguesas, que mais se orientam a uma melhoria contínua. Merece destaque o Museu Soares dos Reis em suas atitudes inovadoras na ampliação do seu público. Contudo, Santos e Varejão (2015) afirmam que, considerando-se as mudanças no campo dos museus, o Museu Soares dos Reis requer um esforço de soluções inovadoras em gestão.

REAd | Porto Alegre - Vol. 23 - No Especial - Dezembro 2017 - p. 292-316 
Quanto ao gerenciamento do desempenho existente nas instituições brasileiras, ele é desenvolvido levando-se em consideração indicadores estabelecidos para tal fim, mas, na maioria, de forma que satisfaçam as informações que devem estar contidas nos relatórios de gestão exigidos pelo governo brasileiro.

Nas instituições portuguesas, todas possuem indicadores, mas nem todas se valem deles para as tomadas de decisões estratégicas. As únicas instituições portuguesas que informaram se valerem dos indicadores para tratar de questões relacionadas com o alinhamento estratégico foi o Arquivo do Porto. Santos e Varejão (2015) descrevem que as generalizações de indicadores no Museu Soares do Reis são reduzidas, limitando-se à quantificação de visitantes, satisfação, tempo, custos e produtividade.

O planejamento existe nas instituições brasileiras por força dos planos plurianuais que devem ser desenvolvidos e dos orçamentos, que devem ser apresentados por imposições legais aos órgãos públicos federais. Contudo, a grande questão é se possuem um caráter estratégico. Quanto às instituições portuguesas (Museu, Arquivo e Biblioteca), o planejamento organizacional é desenvolvido tendo em vista que as diretrizes estratégicas são definidas por instâncias superiores. Contudo, somente o Arquivo demonstrou seguir, de forma mais próxima, as orientações que definem seus rumos. Fica claro que o modelo de gestão estratégica não é seguido pelas instituições, tanto no Brasil quanto em Portugal.

Por fim, todas as instituições não se utilizam das informações vindas do ambiente para direcionarem suas estratégias.

\subsection{OS PROCESSOS}

O segundo componente para a definição da existência do alinhamento estratégico é o processo. Aqui, entendido como a forma de implementação da estratégia na organização e o controle de sua execução. Duas abordagens podem ser constituídas para a implementação estratégica. Uma delas é a adoção da orientação por processos e a outra, a abordagem por orientação funcional.

Pode-se constatar que as três instituições brasileiras e as três portuguesas adotam a abordagem orientada por função. Possuem uma estrutura organizacional hierarquizada e uma centralização do processo decisório, o que confirma o modelo de gestão mecanicista.

Tanto o Arquivo Nacional quanto a Biblioteca Nacional no Brasil, possuem iniciativas de adoção da abordagem por processos. Inclusive, existem alguns processos

REAd | Porto Alegre - Vol. 23 - No Especial - Dezembro 2017 - p. 292-316 
mapeados, mas de forma embrionária, e não demonstram relevância para a sua análise. O mesmo ocorre com as instituições portuguesas, que são hierarquizadas e adotam uma orientação funcional. Santos e Varejão (2015) confirmam, para o caso do Museu Nacional Soares do Reis, que há rigidez de procedimentos e ausência de autonomia e, ainda, concentração e centralização. Prosseguem os autores que o Museu Soares dos Reis, na dimensão organizacional e de gestão, configura-se de forma hierarquicamente concentrada e rígida. O que vem ao encontro de uma organização hierarquizada.

No caso do Arquivo do Porto e da Biblioteca Municipal do Porto, ambas adotam o conceito de gestão DE processos, e não de gestão POR processos, por força das orientações da Câmara Municipal do Porto. A gestão por processos é transversal, ou seja, ponta a ponta, e, no caso das instituições mencionadas, a abordagem é centralizada, com a ligação entre os fragmentos de processo existentes nas áreas organizacionais. As unidades administrativas operam cada parte dos processos, e as transferências ocorrem nas mudanças de órgão, e não em um fluxo contínuo.

A Câmara Municipal possui documentação orientada para processos, mas o que se constata nas instituições portuguesas é que a prática não corresponde ao plano formal de atuação/operação nas instituições conforme as diretrizes estabelecidas pela Câmara Municipal do Porto.

A abordagem funcional é adotada pelas três instituições brasileiras e, também, pelas instituições portuguesas, que possuem uma dinâmica informacional entre os vários ambientes organizacionais limitada devido às características do modelo mecanicista, que não permite fluir a informação de forma que o acoplamento entre unidades organizacionais seja mais integrado (VALENTIM, 2010). Os ambientes informacionais estão correlacionados aos níveis hierárquicos da organização, ou seja, ao nível estratégico, ao nível tático e ao nível operacional, porém, com reduzido fluxo informacional, restringindo-se ao que é exigido pelas atividades desenvolvidas. O que demonstra alta concentração nos fluxos e baixa comunicação entre as áreas.

Nesse modelo, é comum a descida de fluxos pelos níveis hierárquicos, do estratégico ao operacional, onde a informação deve se propagar a fim de desenvolver a execução estratégica e construir a integração organizacional. E subir fluxo de informações do nível operacional ao estratégico para acompanhamento e controle das operações e projetos organizacionais.

A pesquisa não se preocupou com a abrangência e aprofundamento das informações

REAd | Porto Alegre - Vol. 23 - No Especial - Dezembro 2017 - p. 292-316 
contidas nos planos desdobrados, bem como dos indicadores de desempenho desenvolvidos, ou seja, não foi objeto da pesquisa avaliar conteúdo e, sim, o movimento (processo) da realização estratégica. Nesse sentido, as instituições pesquisadas, teoricamente, cumprem o estabelecido para a implementação estratégica.

Enfim, não é uma cultura das instituições brasileiras e portuguesas utilizar a informação como elemento fundamental para a tomada de decisão, o que ocorre muitas vezes numa forma intuitiva. Os indicadores não são analisados sistematicamente para gerarem informações que subsidiem o alinhamento estratégico. As informações extraídas dos indicadores ou quando da ocorrência de alguma irregularidade ou anomalias, em alguns casos, são consideradas nas instituições portuguesas: nos Arquivos, com mais intensidade e, nas Bibliotecas, em alguns casos, para a resolução de problemas ou para a melhoria contínua.

\subsection{AS PESSOAS}

O terceiro componente para a definição da existência do alinhamento estratégico está relacionado às pessoas. É nele em que serão encontrados os elementos que permitirão avaliar a existência de uma capacitação apropriada para a construção do alinhamento.

Apesar de as instituições brasileiras e portuguesas, cada uma à sua maneira, estimularem a participação dos colaboradores no planejamento, no quesito capacitação orientada para a estratégia, todas apresentaram a mesma situação de inexistência de um plano de capacitação que busque atender ao alinhamento estratégico especificamente.

No caso das instituições portuguesas, ocorre que, pela situação do país, restrições financeiras impossibilitam vários aspectos de desenvolvimento das instituições, como é o caso dos processos de desenvolvimento e capacitação. Situação essa em que, no período da pesquisa, não se encontrava o Brasil.

A área de Recursos Humanos da Câmara Municipal está substituindo vários planos de formação de pessoas de externos para internos, com vista a atender às demandas e não estar condicionada à inexistência de recursos para a capacitação do pessoal. Da mesma forma, essas instituições não promovem concurso há vários anos, o que provoca a não renovação de seus quadros. Não é prática sistemática nas instituições brasileiras e portuguesas a formação de times de trabalho e a adoção de práticas colaborativas no dia a dia para desenvolvimento das atividades, salvo em movimentos orientados de forma específica para projetos, no caso dos Museus ou de resolução de problemas nos demais casos.

REAd | Porto Alegre - Vol. 23 - No Especial - Dezembro 2017 - p. 292-316 
Finalmente, cabe destacar que um problema que pode se agravar com o decorrer do tempo nas instituições portuguesas, e que também atinge as instituições brasileiras de forma mais branda, está relacionado com o conhecimento e sua conservação. Em função da baixa renovação dos quadros de pessoal e a baixa preocupação de manutenção da memória e conhecimento da organização, tudo pode ser posto a se perder, considerando-se as perdas de capital humano decorrente de saídas por tempo de serviço.

\section{CONSIDERAÇÕES FINAIS}

Este trabalho procurou avaliar a informação aplicada ao alinhamento estratégico com ênfase na relação entre o propósito, os processos e as pessoas em organizações de captação, de processamento e de disseminação de informação. Foram selecionados para a pesquisa a Biblioteca Nacional, o Museu Nacional e o Arquivo Nacional no Brasil e o Museu Soares dos Reis, a Biblioteca Municipal do Porto e o Arquivo do Porto em Portugal.

Ao longo do trabalho, procurou-se relacionar a dinâmica das instituições com o alinhamento estratégico para efeito da integração organizacional, tendo-se em vista a consecução de seus objetivos estratégicos.

A instituição que parece estar mais sintonizada com o seu ambiente é o Museu Histórico Nacional no Brasil, em seguida a Biblioteca Nacional e, depois, o Arquivo Nacional no Brasil.

Constatou-se que o Museu Histórico Nacional é muito criterioso no aspecto do planejamento, principalmente, quanto a uma abordagem metodológica de forma a mobilizar toda a instituição. Muito tem a ver com a sua direção, que desenvolveu essa cultura ao longo dos vinte anos à frente do Museu.

O Arquivo Nacional, também, com uma direção de trinta anos, tem se preocupado com a elaboração do planejamento para, principalmente, construir o orçamento da instituição. Com características distintas e estilos gerenciais específicos, demonstram uma busca para o alinhamento estratégico das instituições. Contudo, cabe destacar que o Museu Histórico Nacional, pelas informações e observações realizadas, possui um nível de maturidade maior que o do Arquivo Nacional quanto ao seu desempenho na formulação e procedimentos para o desdobramento estratégico.

No caso português, merece destaque a atuação da Câmara Municipal do Porto e, principalmente, do Arquivo Geral que, com seu Sistema Geral da Qualidade, busca o

REAd | Porto Alegre - Vol. 23 - No Especial - Dezembro 2017 - p. 292-316 
alinhamento estratégico, diferenciando-se das demais instituições.

Nas instituições portuguesas, a sintonia com o ambiente é baixa, cabendo ao Museu Soares dos Reis uma maior dinâmica com seus usuários.

Todas as instituições, brasileiras e portuguesas, apresentam uma estrutura organizacional rígida e permanente. Observando-se, ainda, a centralização, o que vem ao encontro da característica de autoridade baseada na hierarquia e no comando, mas pôde se observar que as instituições têm flexibilidade nesse aspecto.

Há uma preocupação das três instituições no Brasil de que o sistema de comunicação seja tanto vertical quanto horizontal. Nas instituições portuguesas, prevalece a comunicação vertical com alguma interação com a gestão das instituições.

Por sofrerem controle e estarem expostos a um acompanhamento por organismos não só governamentais, como também da própria sociedade, as instituições, no Brasil e em Portugal, procuram ater-se a regras e regulamentos formalizados. Apesar disso, não possuem manuais normativos quanto aos processos em funcionamento de forma a descreverem os procedimentos operacionais em muitas situações, à exceção da Câmara Municipal do Porto, que merece destaque pela documentação e diretrizes emanadas para seus serviços, em que a Biblioteca e o Arquivo se inserem.

A Tecnologia da Informação não apoia as questões estratégicas, limitando-se a melhorias dos problemas operacionais em todas as instituições, tanto brasileiras quanto portuguesas.

O gerenciamento do desempenho das instituições brasileiras e portuguesas não é desenvolvido e os indicadores de desempenho são utilizados para cumprir exigências de instâncias superiores e os que são desenvolvidos cumprem seus benefícios somente no nível operacional, como é o caso do Arquivo Geral do Porto.

De maneira geral, as instituições pesquisadas apresentam uma forte influência no seu modelo de gestão tradicional por serem organismos públicos e estarem condicionadas às regulamentações inerentes a essa situação. Contudo, pôde se observar, nas entrevistas realizadas, que existem ações institucionais que as aproximam de modelos mais contemporâneos de gestão. Em todas as instituições, há predominância do modelo mecanicista, contudo podem se observar indicações do modelo toyotista, principalmente, no Arquivo Geral, que é impulsionado pela Câmara Municipal do Porto. O que sinaliza uma cultura organizacional, tanto no Brasil quanto em Portugal, por ser mais rígida e burocrática nesse modelo, como um possível dificultador do alinhamento estratégico.

REAd | Porto Alegre - Vol. 23 - No Especial - Dezembro 2017 - p. 292-316 
O Quadro 1, a seguir, apresenta a situação identificada no Brasil e representa uma síntese do estudo desenvolvido. Como apresentado, o alinhamento estratégico é desenvolvido em cada uma das instituições estudadas, contudo a integração entre propósito, processo e pesquisa, não. Destaca-se o Museu Histórico Nacional que, embora de caráter informal, possui uma média integração entre os três componentes pesquisados.

Quadro 1 - Situação das instituições no Brasil

\begin{tabular}{|l|c|c|c|}
\hline & Museu Histórico Nacional & Arquivo Nacional & Biblioteca Nacional \\
\hline Alinhamento Estratégico & Sim & Sim & Não \\
\hline $\begin{array}{l}\text { Integração entre Propósito, } \\
\text { Processo e Pessoas }\end{array}$ & Médio & Baixa & Baixa \\
\hline
\end{tabular}

Fonte: elaborado pelo autor.

Da mesma forma, o Quadro 2 apresenta uma síntese das conclusões deste trabalho. No que se refere ao alinhamento estratégico, pode se observar que o Arquivo Geral do Porto desenvolve o alinhamento estratégico parcialmente e as demais instituições, não. Igualmente, a integração entre propósito, processo e pessoas é desenvolvida em maior intensidade comparativamente com as demais instituições.

Quadro 2 - Situação das instituições em Portugal

\begin{tabular}{|l|c|c|c|}
\hline & $\begin{array}{c}\text { Museu Nacional Soares dos } \\
\text { Reis }\end{array}$ & $\begin{array}{c}\text { Arquivo Geral do } \\
\text { Porto }\end{array}$ & $\begin{array}{c}\text { Biblioteca Municipal } \\
\text { do Porto }\end{array}$ \\
\hline Alinhamento Estratégico & Não & Parcial & Não \\
\hline $\begin{array}{l}\text { Integração entre Propósito, } \\
\text { Processo e Pessoas }\end{array}$ & Baixa & Média & Baixa \\
\hline
\end{tabular}

Fonte: elaborado pelo autor.

Pode se concluir que as instituições brasileiras e portuguesas não carregam na informação a forma para a construção do alinhamento estratégico e, também, não buscam a sua diferenciação baseada na informação. Constata-se, ainda, que não existe uma única forma de buscarem o alinhamento e que a Câmara Municipal do Porto e as instituições pesquisadas possuem elementos para a sua realização, entretanto, sem aproveitá-los na sua plenitude.

O resultado da pesquisa não finaliza com sua contribuição para o entendimento das organizações de captação, processamento e disseminação da informação. Contribuiu para o entendimento do modelo de gestão das organizações pesquisadas, de como funcionam e

REAd | Porto Alegre - Vol. 23 - No Especial - Dezembro 2017 - p. 292-316 
articulam a informação para efeito de sua integração estratégica, em que os resultados, pode se afirmar, foram positivos na construção desse entendimento.

Concluímos, com o estudo, que é importante reconhecer, em primeiro lugar, que o conhecimento em uma perspectiva global, os objetivos e as estratégias devem nortear as ações organizacionais, o que faz com que se considere a informação como um processo contínuo para a criação e tomada de decisão. Em segundo lugar, substituir a visão fragmentada da tarefa por um modelo de gestão que favoreça uma maior integração e que crie ou ajude a criar valor para a organização e todas as partes por ela interessadas. Em terceiro lugar, promover a integração da Tecnologia da Informação aos serviços prestados de forma que faça parte do processo e da organização, como mais um recurso, como um meio e não como um fim. Por último, há que disseminar e internalizar esses tipos de competências por toda a Organização.

Finalmente, a pesquisa identificou uma nova possibilidade de aprofundamento do estudo com a incorporação do consumidor/usuário dos serviços das instituições, por meio de sua participação, gerando informações que permitam o aprimoramento das organizações.

Agradecimentos

Às instituições e seus colaboradores, pela disponibilidade e informações prestadas durante o desenvolvimento da pesquisa.

À Coordenação de Aperfeiçoamento de Pessoal de Nível Superior (CAPES), pelo financiamento do projeto que deu origem a este artigo.

\section{REFERÊNCIAS}

AFONSO, F. I. P. Avaliação de desempenho enquanto ferramenta para prossecução da estratégia organizacional: estudo sobre MCG. 2014. 161 f. Dissertação (Mestrado em Gestão)- Instituto Universitário de Lisboa, Lisboa, 2014. Disponível em: http://hdl.handle.net/10071/6478. Acesso em: 20 fev. 2015.

ALVES-MAZZOT, A. J.; GEWANDSNAJDER, F. O método nas ciências naturais e sociais. Pioneira: São Paulo, 2000.

ALBERTI, V. História oral: a experiência do Cpdoc. Rio de Janeiro: FGV, 1990. AKAO, Y. Hoshin Kanri, policy deployment for successful TQM. New York: Produtivity Press, 1991.

BUNGAY, S. The art of action: how leaders close the gaps between plans, action and

REAd | Porto Alegre - Vol. 23 - No Especial - Dezembro 2017 - p. 292-316 
results. Boston: Nicholas Brealey Publishing, 2011.

CAMPOS, V. F. Gerenciamento pelas diretrizes. Belo Horizonte: Fundação Cristiane Otoni, 1996.

CARVALHO, M. M. de; PRIETO, V. C.; BOUER, R. Maximização da estratégia: promovendo resultados por meio do alinhamento, execução e medição. Rio de Janeiro: Campus, 2012.

CERVO, A. L.; BERVIAN, P. A. Metodologia científica. São Paulo: Prentice Hall, 2002. CHIAVENATO, I. Introdução à teoria geral da administração: uma visão abrangente da moderna administração das organizações. Rio de Janeiro: Elsevier, 2003.

CRISPIM, S.; LUGOBONI, L. Avaliação de desempenho organizacional: análise comparativa dos modelos teóricos e pesquisa de aplicação nas Instituições de Ensino Superior da Região Metropolitana de São Paulo, Revista Portuguesa e Brasileira de Gestão, Lisboa, v. 11, n. 1, p.41-54, jan./mar. 2012. Disponível em: http://www.redalyc.org/pdf/3885/388539132005.pdf. Acesso em: 20 out. 2015.

DURAND, T. A'Alchimie de la competence. Revue française de gestion, France, v. 1, n. 160, p. 261-292, 2006. Disponível em: https://www.cairn.info/revue-francaise-de-gestion2006-1-page-261.htm. Acesso em: 10 out. 2015.

FERLIE, E.; ONGARO, E. Strategic management in public services organizations: concepts, schools, and contemporary issues. London: Routledge, 2015. FERREIRA, V. C. P. et al. Modelos de gestão. Rio de Janeiro: FGV, 2005. FITERMAN, L.; SILVA, A. B. A utilização de modelos de avaliação de desempenho no suporte à tomada de decisão. In: ENCONTRO NACIONAL DE ENGENHARIA DE PRODUÇÃO, 27., 2007. Anais... Foz do Iguaçu: ABEPRO, 2007. Disponível em: <http://www.abepro.org.br/biblioteca/enegep2007_tr640478_9901.pdf. Acesso em: 12 out. 2015.

GALBRAITH, J. R. Organization design: an information processing view. Organizational Effectiveness Center and School, Bingley, UK, v. 21, p. 21-26, 1977.

GALBRAITH, J.R; DOWNEY, D.; KATES, A. Projeto de organizações dinâmicas: um guia prático para líderes de todos os níveis. Porto Alegre: Bookman, 2011.

GONÇALVES, J. E. L. As empresas são grandes coleções de processos. Revista de Administração de Empresas, São Paulo, v. 40, n. 1, p. 6-19, jan./mar. 2000. Disponível em: http://www.scielo.br/pdf/rae/v40n1/v40n1a02.pdf. Acesso em: 10 out. 2015.

HARMON, P. Business process change: a guide for business managers and BPM and six

REAd | Porto Alegre - Vol. 23 - No Especial - Dezembro 2017 - p. 292-316 
sigma professionals. 2 ed., Oxford: Elsevier, 2007.

HEIJDEN, K.V.D. Planejamento de cenários: a arte da conversação estratégica. Porto Alegre: Bookman, 2009.

KAPLAN, R.S.; NORTON, D.P. Estratégia em ação: Balance Scorecard. Rio de Janeiro: Campus, 1997.

KOHLBACHER, M. The effects of process orientation: a literature review. Business Process Management Journal, Bingley, v. 16, n. 1, p. 135-152, 2010.

MORRISON, E. D. et al. Strategic alignment of business processes. In: INTERNATIONAL WORKSHOP ON ENGINEERING SERVICE-ORIENTED APPLICATIONS, 7., 2011, Paphos, Cyprus. Annals... Paphos: University of Wollongong Australia, 2011. Disponível em: http://ro.uow.edu.au/cgi/viewcontent.cgi?article=2281\&context=infopapers. Acesso em: 7 mar. 2015.

MCGEE, J. V.; PRUSAK, L. Gerenciamento estratégico da informação: aumente a competitividade e a eficiência de sua empresa utilizando a informação como uma ferramenta estratégica. Rio de Janeiro: Campus, 1994.

MINTZBERG, H.; QUINN, J. B. O processo da estratégia. Porto Alegre: Bookman, 2001. OLIVEIRA, J. F. C; PINHEIRO, L. V. R.; ANDRADE, A. R. Informação como objeto para a construção do corpus interdisciplinar entre Ciência da Informação e Ciência da Administração. Liinc em Revista, Rio de Janeiro, v. 7, n. 1, p. 61-81, mar. 2011. Disponível em: http://revista.ibict.br/liinc/article/view/3289/2905. Acesso em: 7 mar. 2015. PRIETO, V. C.; CARVALHO, M. M. Análise do Alinhamento Estratégico e o Impacto nos Resultados no Setor de Medicina Diagnóstica. In: ENCONTRO DA ASSOCIAÇÃO NACIONAL DE PÓS-GRADUAÇÃO E PESQUISA EM ADMINISTRAÇÃO, 28., 2004, Curitiba, 2004. Anais... Curitiba: ANPAD, 2004. Disponível em:

http://www.anpad.org.br/diversos/trabalhos/EnANPAD/enanpad_2004/ESO/2004_ESO2895. pdf. Acesso em:7 mar. 2015.

PORTER, M. E. A vantagem competitiva das nações. MONTGOMERY, C. A; PORTER, M. E. (Org). Estratégia: a busca da vantagem competitiva. Rio de Janeiro: Campus, 1998. RODRIGUES, M.V. R. y. Gestão do Conhecimento: reinventando a empresa para uma sociedade baseada em valores intangíveis. Rio de Janeiro: IBPI Press, 2010.

ROSEMANN, M.; BROCKE, J. von. The six core elements of business process management. BROCKE, J. von; ROSEMANN, M. (Ed.). Handbook on business process management 1: introduction, methods, and information systems. 2.ed. New York: Springer Berlin Heidelberg, 
2015. p.105-122.

SANTOS, H, VAREJAO, J. Dinâmicas e desafios dos museus públicos: resultado do estudo realizado no Museu Nacional Soares dos Reis. Porto: FEL; MNSR, 2015. Disponível em: <http://www.museusoaresdosreis.pt/>. Acesso em: fev. 2015.

SOBRAL, F.; PECI, A. Administração: teoria e prática no contexto brasileiro. São Paulo: Pearson, 2013.

TENÓRIO, F. G. Flexibilização organizacional: mito ou realidade? Rio de Janeiro: FGV, 2000.

YIN, R. Estudo de caso: planejamento e métodos. Porto Alegre: Bookman, 2001.

VALENTIM, M. (Org.) Ambientes e fluxos de informação. São Paulo: Cultura Acadêmica, 2010.

ZARAFIAN, P. A. Objetivo competência: por uma nova lógica. São Paulo: Atlas, 2001. 